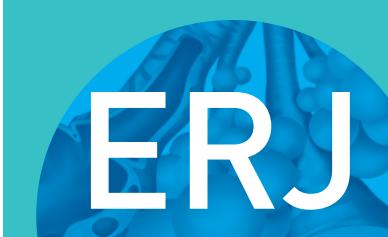

open research
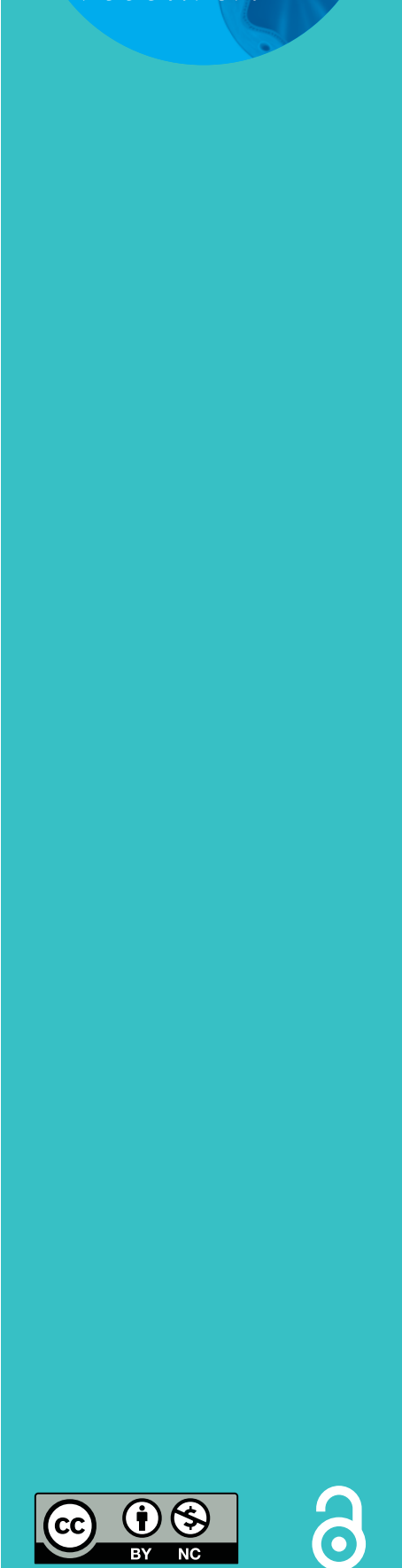

\title{
Pulmonary haemodynamic response to exercise in highlanders versus lowlanders
}

\author{
Silvia Utrich (10 ${ }^{1,4}$, Stéphanie Saxer (10 ${ }^{1,4}$, Michael Furian (1) ${ }^{1}$, Patrick R. Bader ${ }^{1}$, \\ Paula Appenzeller ${ }^{1}$, Philipp M. Scheiwiller ${ }^{1}$, Maamed Mademilov \\ Ulan Sheraliev², Felix Tanner ${ }^{3}$, Talantbek M. Sooronbaev², Konrad E. Bloch ${ }^{1}$ and \\ Mona Lichtblau (1) 1
}

Affiliations: ${ }^{1}$ Dept of Pulmonology, University Hospital Zurich, Zurich, Switzerland. ${ }^{2}$ National Center for Cardiology and Internal Medicine, Bishkek, Kyrgyzstan. ${ }^{3}$ Dept of Cardiology, University Hospital Zurich, Zurich, Switzerland. ${ }^{4}$ These authors contributed equally.

Correspondence: Silvia Ulrich, Dept of Pulmonology, University Hospital Zurich, Rämistrasse 100, CH-8091 Zurich, Switzerland. E-mail: silvia.ulrich@usz.ch

ABSTRACT The aim of the study was to investigate the pulmonary haemodynamic response to exercise in Central Asian high- and lowlanders.

This was a cross-sectional study in Central Asian highlanders (living $>2500 \mathrm{~m}$ ) compared with lowlanders (living $<800 \mathrm{~m}$ ), assessing cardiac function, including tricuspid regurgitation pressure gradient (TRPG), cardiac index and tricuspid annular plane systolic excursion (TAPSE) by echocardiography combined with heart rate and oxygen saturation measured by pulse oximetry $\left(S_{\mathrm{pO}_{2}}\right)$ during submaximal stepwise cycle exercise $(10 \mathrm{~W}$ increase per $3 \mathrm{~min}$ ) at their altitude of residence (at $760 \mathrm{~m}$ or $3250 \mathrm{~m}$, respectively).

52 highlanders (26 females; aged $47.9 \pm 10.7$ years; body mass index (BMI) $26.7 \pm 4.6 \mathrm{~kg} \cdot \mathrm{m}^{-2}$; heart rate $75 \pm 11$ beats $\cdot \mathrm{min}^{-1} ; S_{\mathrm{pO}_{2}} 91 \pm 5 \% ;$ ) and 22 lowlanders (eight females; age $42.3 \pm 8.0$ years; BMI $26.9 \pm 4.1 \mathrm{~kg} \cdot \mathrm{m}^{-2}$; heart rate $68 \pm 7$ beats $\left.\cdot \mathrm{min}^{-1} ; S_{\mathrm{pO}_{2}} 96 \pm 1 \%\right)$ were studied. Highlanders had a lower resting $S_{\mathrm{pO}_{2}}$ compared to lowlanders but change during exercise was similar between groups (highlanders versus lowlanders $-1.4 \pm 2.9 \%$ versus $-0.4 \pm 1.1 \%$, respectively, $\mathrm{p}=0.133$ ). Highlanders had a significantly elevated TRPG and exercise-induced increase was significantly higher $(13.6 \pm 10.5 \mathrm{mmHg}$ versus $6.1 \pm 4.8 \mathrm{mmHg}$, difference 7.5 (2.8 to 12.2$) \mathrm{mmHg} ; \mathrm{p}=0.002)$, whereas cardiac index increase was slightly lower in highlanders $\left(2.02 \pm 0.89 \mathrm{~L} \cdot \mathrm{min}^{-1}\right.$ versus $1.78 \pm 0.61 \mathrm{~L} \cdot \mathrm{min}^{-1}$, difference $0.24(-0.13$ to 0.61$) \mathrm{L} \cdot \mathrm{min}^{-1}$; $\mathrm{p}=0.206)$ resulting in a significantly steeper pressure-flow ratio $(\Delta \mathrm{TRPG} / \Delta$ cardiac index $)$ in highlanders 9.4 $\pm 11.4 \mathrm{WU}$ and lowlanders 3.0 $\pm 2.4 \mathrm{WU}$ (difference 6.4 (1.4 to 11.3) WU; p=0.012). Right ventriculararterial coupling (TAPSE/TRPG) was significantly lower in highlanders but no significant difference in change with exercise in between groups was detected $(-0.01(-0.20$ to 0.18$) ; \mathrm{p}=0.901)$.

In highlanders, chronic exposure to hypoxia leads to higher pulmonary artery pressure and a steeper pressure-flow relation during exercise.

@ERSpublications

Central Asian highlanders living between 2500 and $3600 \mathrm{~m}$ assessed by stress echocardiography showed that chronic exposure to hypoxia leads to a steeper pressure-flow curve during exercise and worse right ventricular-arterial coupling compared to lowlanders https://bit.ly/3qlvhOj

Cite this article as: Ulrich $\mathrm{S}$, Saxer $\mathrm{S}$, Furian $\mathrm{M}$, et al. Pulmonary haemodynamic response to exercise in highlanders versus lowlanders. ERJ Open Res 2021; 7: 00937-2020 [https://doi.org/ 10.1183/23120541.00937-2020].

This article has supplementary material available from openres.ersjournals.com

This study is registered at www.ClinicalTrials.gov with identifier number NCT03165656. Data availability: Individual data will be shared upon request to the corresponding author.

Received: 14 Dec 2020 | Accepted: 22 Dec 2020

Copyright $\odot$ The authors 2021. This version is distributed under the terms of the Creative Commons Attribution NonCommercial Licence 4.0. For commercial reproduction rights and permissions contact permissions@ersnet.org 


\section{Introduction}

Millions of people worldwide are permanently living above $2500 \mathrm{~m}$ altitude raising interest in uncovering the pathophysiological adaption to high altitude. In Andean or Tibetan individuals living at altitudes between 3600 and $4350 \mathrm{~m}$, an elevated pulmonary artery pressure (PAP) at rest and during exercise has been reported compared with lowlanders [1,2], with highest values in patients with chronic mountain sickness (CMS) [3]. Recently, we found a slightly but significantly elevated PAP at rest in a large cohort of Central Asian highlanders living at altitudes between 2500 and $3600 \mathrm{~m}$ compared with lowlanders, along with distinct alterations in cardiac function [4]. However, albeit depending on the definition used, high-altitude pulmonary hypertension $(\mathrm{HAPH})$ according to resting pulmonary haemodynamics in high altitude dwellers appears to be rare $[1,2,4]$. An abnormal pulmonary haemodynamic response to exercise may cause dyspnoea and may precede manifest resting pulmonary hypertension in subjects at risk including those permanently exposed to a hypoxic environment at altitude [5]. Exercise pulmonary hypertension is characterised by a steeper increase in PAP in relation to the increase in pulmonary blood flow, measured as cardiac output during exercise [6]. In 1966, exercise right heart catheterisation was performed in 35 highlanders at $4500 \mathrm{~m}$ and revealed a larger increase in mean PAP from $29 \mathrm{mmHg}$ to $60 \mathrm{mmHg}$ during moderate exercise compared to lowlanders (from $12 \mathrm{mmHg}$ to $18 \mathrm{mmHg}$ ) along with a significant desaturation during exercise whereas the change in cardiac output was mainly driven by an increase in heart rate and was comparable to controls near sea level [7]. However, performing invasive right heart catheterisations in remote areas is technically challenging and, nowadays, often considered unethical as it is an invasive procedure in presumably healthy subjects. Echocardiography has been established as a useful non-invasive and reliable tool to assess right heart function during exercise $[8,9]$ and is thus especially suited for rural regions.

Exercise haemodynamics have not been assessed in Central Asian highlanders living at a moderate-to-high altitude between 2500 and $3600 \mathrm{~m}$ such as the Kyrgyz high altitude dwellers in the Tien Shan mountain range and have not been compared with lowlanders of the same ethnicity. It is not known whether these subjects chronically exposed to a hypobaric hypoxic environment would reveal a pathological haemodynamic response to exercise as potential early sign of imminent $\mathrm{HAPH}$.

Therefore, the aim of the current trial was to investigate changes of pulmonary haemodynamics and heart function during stepwise incremental exercise in highlanders living between 2500 and $3600 \mathrm{~m}$ free of manifest diseases including CMS compared with healthy lowlanders.

\section{Methods}

This cross-sectional study was conducted in the National Center for Cardiology and Internal Medicine, Bishkek $(760 \mathrm{~m})$ and in the Ak-Say region of the Tien Shan mountain range at an altitude of $3250 \mathrm{~m}$, both in Kyrgyzstan, from July to August, 2017. Healthy lowlanders and highlanders (living between 2500 and $3600 \mathrm{~m}$ ) without overt cardiopulmonary diseases including absence of CMS were invited to participate in this study. This study was part of a larger trial registered at clinicaltrials.gov: NCT03165656.

\section{Participants}

Kyrgyz lowlanders (born, raised and living $<800 \mathrm{~m}$ ) and highlanders (born, raised and currently living $>2500 \mathrm{~m}$ ) of both sexes, aged $\geqslant 16$ years, were recruited among outpatients of the National Center for Cardiology and Internal Medicine in Bishkek or in the Ak-Say region, respectively. Highlanders were excluded if they had excessive erythrocytosis as an indicator of CMS (defined as haemoglobin $>19 \mathrm{~g} \cdot \mathrm{dL}^{-1}$ in females and $>21 \mathrm{~g} \cdot \mathrm{dL}^{-1}$ in males) or other relevant cardiopulmonary diseases, such as coronary heart disease, chronic obstructive pulmonary disease or heavy smoking $\left(>20\right.$ cigarettes $\cdot$ day $\left.^{-1}\right)$. This study was conducted in accordance with the Declaration of Helsinki, approved by the ethics committee in Kyrgyzstan (01-8/433), and all participants gave written informed consent to participate in the study.

\section{Assessments}

Echocardiographic recordings were obtained with a real-time, phased array sector scanner (CX 50, Philips, Philips Respironics, Zofingen, Switzerland) with an integrated Color Doppler system and a transducer containing crystal sets for imaging (1-5 MHz) and for continuous-wave Doppler. Recording and analysis were performed according to guidelines of the European Association of Echocardiography [10]. Measurements were performed at rest and during cycling exercises both in upright position on a cycle ergometer. Patients performed a stepwise incremental exercise test with increase of $10 \mathrm{~W}$ every $3 \mathrm{~min}$. At each step echocardiographic measures as described below were performed and heart rate, blood pressure and oxygen saturation by pulse oximetry $\left(S_{\mathrm{pO}_{2}}\right)$ were measured. Tricuspid regurgitation pressure gradient (TRPG) was calculated from maximal tricuspid regurgitation velocity (TRVmax) obtained with continuous-wave Doppler using the modified Bernoulli equation: $\Delta \mathrm{P}=4 \times \mathrm{Vmax}^{2}$. As the right atrium pressure by echocardiography is estimated from the collapsibility of the vena cava at rest and cannot be 
assumed as constant during exercise [11], we provided the measured TRPG as surrogate for the PAP during exercise. For systolic PAP (sPAP) estimates, we added the right atrial pressure of $5 \mathrm{mmHg}$ to the TRPG. Mean PAP (mPAP) was calculated from sPAP with the formula: $\mathrm{mPAP}=\mathrm{sPAP} \times 0.61+2$ [12]. Systolic and end-diastolic areas of the right ventricle were manually traced. Fractional area change (FAC) of the right ventricle was calculated (end-diastolic right ventricle area - end-systolic right ventricle area/ end-diastolic right ventricle area). Tricuspid annular plane systolic excursion (TAPSE) was measured in M-mode. Cardiac index was estimated by the Doppler velocity time integral method from the left ventricular outflow tract indexed with body surface area [13]. The TRPG/cardiac index ratio at every step was calculated as surrogate for total pulmonary resistance or pressure-flow ratio. The pressure-flow slope was calculated as change of TRPG/change of cardiac index $(\Delta T R P G / \Delta C I)$ with exercise (maximal value minus resting value), additionally, the $\mathrm{mPAP} /$ cardiac output slope was calculated from sPAP estimates. Right ventricle-arterial coupling was estimated by TAPSE/TRPG [14].

\section{Outcomes}

The primary endpoint was the TRPG measured during exercise in highlanders compared with lowlanders expressed in relation to the increasing flow. Secondary endpoints were $S_{\mathrm{pO}_{2}}$, heart rate, cardiac index and further parameters of the right ventricular function (FAC, TAPSE, TAPSE/TRPG) during exercise in highlanders compared with lowlanders.

\section{Analysis and statistics}

Outcomes were analysed per protocol and values are presented as mean \pm SD and mean difference (95\% CI). Patients were included in the analysis when they had at least two valid TRPG measures during exercise. Differences between lowlanders and highlanders were compared by T-tests at baseline and end exercise as well as the difference of the change from baseline to end exercise. Highlanders were divided into three subgroups according to their resting measures for further explorative analysis: a) $\mathrm{mPAP}<20 \mathrm{mmHg}$ : noHAPH; b) mPAP 20-30 mmHg: borderline HAPH; and c) mPAP>30 mmHg: HAPH. Differences between the subgroups were calculated with ANOVA. Linear mixed regression analysis was performed with pressure-flow slope as dependent variable and age, sex and MPAP subgroups as independent variables. Analysis was performed with STATA 15 and a p-value $<0.05$ or $95 \%$ CI of differences not including zero were considered statistically significant.

\section{Results}

The study flow chart is shown in figure 1 and baseline characteristics in table 1 . We included 52 highlanders ( $50 \%$ female, age 47.9 years, BMI $26.7 \mathrm{~kg} \cdot \mathrm{m}^{-2}$ ) and 22 lowlanders ( $36 \%$ female, age 42.3 years, BMI $26.9 \mathrm{~kg} \cdot \mathrm{m}^{-2}$ ), highlanders were on average 5.5 (0 to 11) years older, smaller with a smaller body surface area, but with the same BMI and had a higher heart rate, haemoglobin, haematocrit and lower blood oxygenation compared with lowlanders.
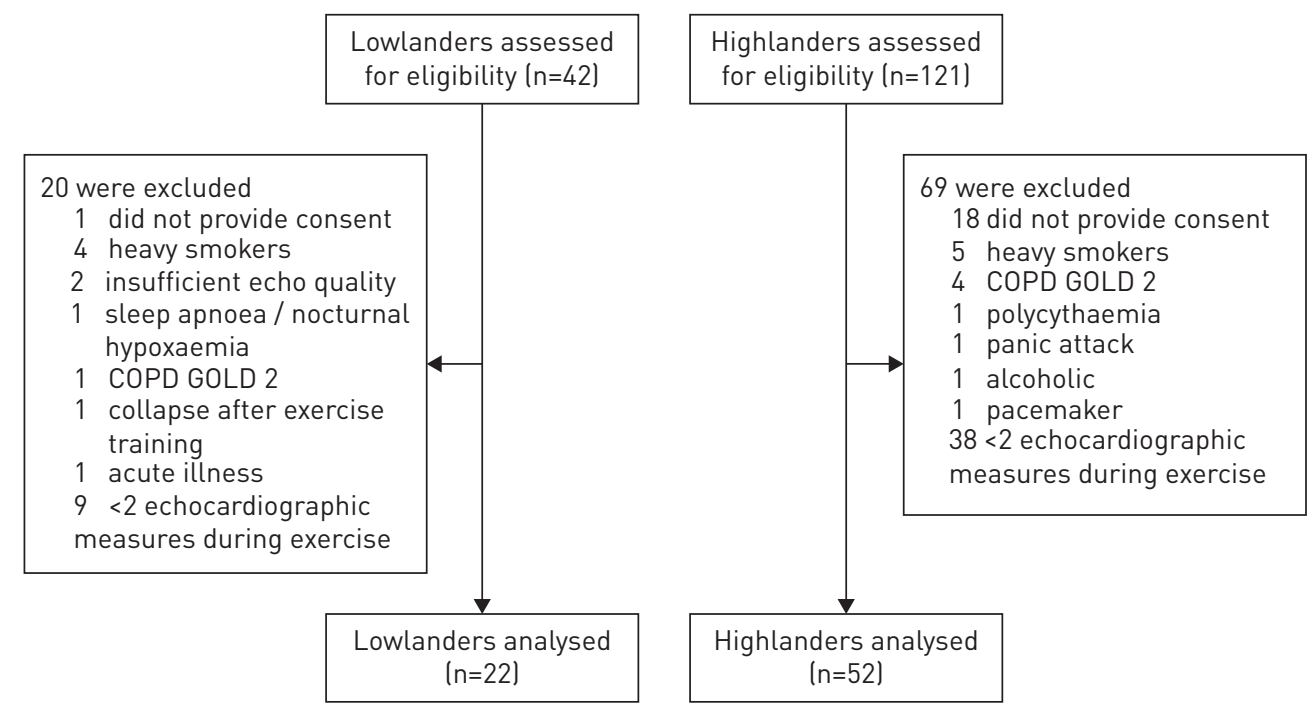

FIGURE 1 Patient flow. GOLD: Global Initiative for Chronic Obstructive Lung Disease. 


\begin{tabular}{|c|c|c|c|}
\hline & Lowlanders $n=22$ & Highlanders $n=52$ & p-value \\
\hline Male/female $\mathbf{n}$ & $14 / 8$ & $26 / 26$ & \\
\hline Age years & $42.3 \pm 8.0$ & $47.9 \pm 10.7$ & 0.033 \\
\hline Height $\mathrm{cm}$ & $168.5 \pm 10.4$ & $162.2 \pm 9.4$ & 0.014 \\
\hline Weight kg & $75.9 \pm 10.4$ & $70.2 \pm 13.4$ & 0.078 \\
\hline BMI $\mathrm{kg} \cdot \mathrm{m}^{-2}$ & $26.9 \pm 4.1$ & $26.7 \pm 4.6$ & 0.845 \\
\hline Body surface area $\mathrm{m}^{2}$ & $1.89 \pm 0.16$ & $1.75 \pm 0.19$ & 0.017 \\
\hline Heart rate beats. $\min ^{-1}$ & $68 \pm 7$ & $75 \pm 11$ & 0.010 \\
\hline Blood pressure systolic $\mathrm{mmHg}$ & $121 \pm 15$ & $127 \pm 23$ & 0.274 \\
\hline Blood pressure diastolic $\mathrm{mmHg}$ & $82 \pm 10$ & $85 \pm 12$ & 0.348 \\
\hline New York Heart Association functional class I/II/III & $18 / 3 / 1$ & $30 / 18 / 4$ & 0.379 \\
\hline Workload achieved Watts & $48 \pm 11$ & $45 \pm 14$ & 0.344 \\
\hline $\mathrm{S}_{\mathrm{pO}_{2}} \%$ & $96 \pm 1$ & $91 \pm 5$ & $<0.001$ \\
\hline Haemoglobin concentration $\mathrm{g} \cdot \mathrm{dL}^{-1}$ & $14.4 \pm 1.7$ & $16.0 \pm 2.3$ & 0.008 \\
\hline Haematocrit $\%$ & $39.1 \pm 5.0$ & $46.8 \pm 7.6$ & $<0.001$ \\
\hline$P_{\mathrm{aO}_{2}} \mathrm{mmHg}$ & $79.3 \pm 10.9$ & $56.2 \pm 6.2$ & $<0.001$ \\
\hline$P_{\mathrm{aCO}_{2}} \mathrm{mmHg}$ & $38.9 \pm 2.9$ & $32.5 \pm 2.8$ & $<0.001$ \\
\hline Oxygen content $\mathrm{mL} \mathrm{O}_{2} \cdot \mathrm{dL}^{-1}$ & $18.3 \pm 2.4$ & $18.9 \pm 2.8$ & 0.447 \\
\hline Pack-years & $1.9 \pm 5.2$ & $3.7 \pm 6.2$ & 0.227 \\
\hline
\end{tabular}

Highlanders had a higher TRPG with a significantly higher increase during exercise, which along with a similar cardiac index increase resulted in a significantly steeper pressure-flow slope in highlanders versus lowlanders ( $(\Delta \mathrm{TRPG} / \Delta \mathrm{CI} 9.4 \pm 11.4$ versus $3.0 \pm 2.4, \mathrm{p}=0.012 ; \mathrm{mPAP} /$ cardiac output $3.3 \pm 3.8$ versus $1.0 \pm 0.8$, $\mathrm{p}=0.007$ ) (table 2 and figure $2 \mathrm{a}$ and $\mathrm{b}$ ). Table 3 shows physiological measurements at baseline and end-exercise as well as the change from rest to end-exercise and the between group differences. Highlanders had a lower $S_{\mathrm{pO}_{2}}$ but a similar decrease with exercise compared with lowlanders. Highlanders achieved a higher heart rate at end-exercise versus lowlanders, otherwise heart rate and stroke volume index (SVI) were mostly similar (table 3). However, highlanders were not able to increase their SVI as much as lowlanders and the between-group difference in change from baseline to end-exercise was 3.4 (0.0-6.8), $\mathrm{p}=0.052$, whereas the increase in heart rate was similar (table 3 ).

TAPSE/TRPG was lower in highlanders compared with lowlanders at rest and end-exercise as sign of impaired right ventricle coupling, but the difference in change from baseline to end-exercise between groups was similar (table 3). In figure 3, results of the consecutive exercise steps (baseline, $3 \mathrm{~min}, 6 \mathrm{~min}$, 9 min and individual end-exercise) are shown.

The exploratory subgroup analysis for highlanders (no HAPH versus HAPH borderline versus HAPH) is shown in the supplementary tables 1-3 and illustrated in figure $2 \mathrm{~b}$. Resting baseline measures of these subgroups revealed a significant difference in only systemic systolic blood pressure at rest. During exercise, TRPG was significantly different with a gradual increase from no HAPH to borderline to HAPH (end-exercise $31.0 \pm 10.0$ versus $37.9 \pm 10.2$ versus $54.7 \pm 13.6 \mathrm{mmHg} ; \mathrm{p}=0.002$ ). The TAPSE/TRPG was

\section{TABLE 2 Between-group differences of the pressure-flow slope}

\begin{tabular}{|c|c|c|c|c|}
\hline & Lowlanders & Highlanders & Between group differences & p-value \\
\hline Subjects $\mathbf{n}$ & 22 & 52 & & \\
\hline$\Delta T R P G / \Delta C I$ WU & $3.0 \pm 2.4$ & $9.4 \pm 11.4$ & $6.4(1.4$ to 11.3$)$ & 0.012 \\
\hline$\Delta \mathrm{mPAP} / \triangle \mathrm{CO}$ WU & $1.0 \pm 0.8$ & $3.3 \pm 3.8$ & $2.3(0.6$ to 3.9$)$ & 0.007 \\
\hline
\end{tabular}



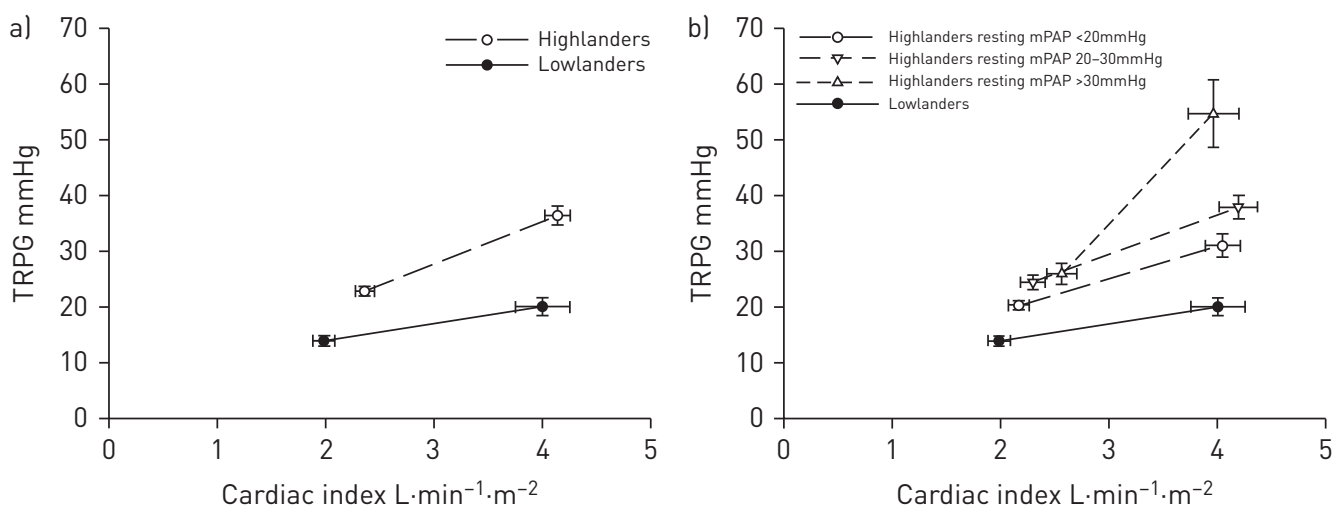

FIGURE 2 Pressure-flow relationship displayed as tricuspid regurgitation pressure gradient (TRPG) in relation to the cardiac index from baseline to end-exercise, reflecting the pressure/flow relationship for (a) highlanders and lowlanders and (b) all groups: lowlanders, no high-altitude pulmonary hypertension (HAPH. resting mean pulmonary artery pressure $\mathrm{mPAP}<20 \mathrm{mmHg}$ ), borderline HAPH (resting mPAP 20-30 mmHg) and HAPH (resting $\mathrm{mPAP}>30 \mathrm{mmHg}$ ).

significantly decreased from noHAPH to $\mathrm{HAPH}$ at end-exercise $(0.89 \pm 0.33$ versus $0.76 \pm 0.33$ versus $\left.0.48 \pm 0.22 \mathrm{~mm} \cdot \mathrm{mmHg}^{-1} ; \mathrm{p}=0.039\right)$ along with a decreasing $S_{\mathrm{pO}_{2}}$ and with significant differences at end-exercise ( $89 \pm 3$ versus $90 \pm 3$ versus $85 \pm 3 \%$; $\mathrm{p}=0.013$ ) and increasing blood pressure. Figure $2 \mathrm{~b}$ and supplementary table 2 show the pressure-flow relationship by subgroups and illustrates a significantly steeper $(\mathrm{p}<0.001)$ increase of the pressure-flow in the HAPH group $(24.5 \pm 4.0)$ compared with the no HAPH (5.4 \pm 3.7$)$ and the borderline HAPH group (9.7 \pm 13.6$)$.

Linear mixed regression analysis revealed that $\triangle \mathrm{TRPG} / \triangle \mathrm{CI}$ depends on the resting $\mathrm{mPAP}$ group (noHAPH, borderline HAPH, HAPH) but is independent of age and sex (supplementary table 4).

\section{Discussion}

This is the first study investigating cardiac function and pulmonary haemodynamics by echocardiography during stepwise cycling exercise in Central Asian highlanders living between 2500 and $3600 \mathrm{~m}$ compared with lowlanders of the same ethnicity. Our main results show that highlanders reveal a significantly steeper pressure-flow slope during exercise due to a higher and more increasing PAP compared with lowlanders along with signs of an impaired right ventricular to arterial coupling at end exercise reflected by a lower TAPSE/TRPG. Within highlanders, the steeper pressure-flow slope on exercise was predicted by exploratory subgroups according to resting mPAP indicating borderline or manifest HAPH.

Previous studies investigating exercise haemodynamics in highlanders versus lowlanders mainly focussed on South American men living at altitudes above $3600 \mathrm{~m}$ in the Andes. In these populations, a higher PAP increase during exercise in highlanders compared with lowlanders was found in 35 healthy men aged 17-35 years who volunteered to undergo cycling exercise right heart catheterisation with a workload of $300 \mathrm{~kg}-\mathrm{m} \cdot \mathrm{min}^{-1} \cdot \mathrm{m}^{-2}\left(50 \mathrm{~W} \cdot \mathrm{m}^{-2}\right)$ near their living altitude at $4540 \mathrm{~m}$ in Bolivia, where the mean PAP increased from 29 to $60 \mathrm{mmHg}$ and in lowlanders from 12 to $18 \mathrm{mmHg}$ [7]. A meta-analysis summarised PAP during exercise echocardiography whilst subjects pedalled semi-supine with $50 \mathrm{~W}$ in 125 highlanders living in South America at altitudes between 3600 and $4350 \mathrm{~m}$ published between 2010 and 2016 [1]. The calculated average TRPG (reported as systolic PAP, i.e. TRPG plus estimated right atrial pressure) at maximal exercise was $36.3 \mathrm{mmHg}$ and $\mathrm{S}_{\mathrm{pO}_{2}}$ was $89.4 \%$ in healthy highlanders and $48.3 \mathrm{mmHg}$ and $82 \%$ in patients with CMS and the increase of TRPG during exercise was $13 \mathrm{mmHg}$ for healthy and $22 \mathrm{mmHg}$ for patients with CMS [1]. In comparison, TRPG in the presently investigated Kyrgyz highlanders was $36.4 \mathrm{mmHg}$, the increase with exercise was $14 \pm 11 \mathrm{mmHg}$ and $S_{\mathrm{pO}_{2}}$ at end-exercise was $89 \%$. Part of the difference in steepness in the pressure-flow of highlanders versus lowlanders may be due to a higher haematocrit [15]. However, the haematocrit was in the normal range in both cohorts. Of note, patients with CMS have been excluded from the current study. In addition, the average cardiac output at exercise in the studies summarised by the meta-analysis was higher compared with the current trial $\left(9.2 \pm 0.9 \mathrm{~L} \cdot \mathrm{min}^{-1}\right.$ versus $\left.7.2 \pm 1.4 \mathrm{~L} \cdot \mathrm{min}^{-1}\right)$ [1]. However, we assume that these were similarly restricted to men, as they were performed by the same teams in the same populations, whereas in our study, half of the highlanders investigated were female. However, the only study we found which differentially reported exercise haemodynamics by echocardiography in men and women revealed a similar pressure-flow slope as ours [16]. In the current trial, we did not detect a significant difference of the pressure-flow in men 


\section{TABLE 3 Assessment during stepwise exercise}

\begin{tabular}{|c|c|c|c|c|}
\hline & Lowlanders & Highlanders & Between group difference & $p$-value \\
\hline Subjects & 22 & 52 & & \\
\hline \multicolumn{5}{|l|}{$\mathrm{S}_{\mathrm{pO}_{2}} \%$} \\
\hline Baseline & $96 \pm 2$ & $91 \pm 3$ & $-5(-6$ to -4$)$ & $<0.001$ \\
\hline End-exercise & $95 \pm 1$ & $89 \pm 3$ & $-6(-8$ to -5$)$ & $<0.001$ \\
\hline End-exercise-baseline & $-0.4 \pm 1.1$ & $-1.4 \pm 2.9$ & $-1.0(-2.2$ to 0.3$)$ & 0.133 \\
\hline \multicolumn{5}{|l|}{ Heart rate beats $\cdot \min ^{-1}$} \\
\hline Baseline & $77 \pm 13$ & $82 \pm 12$ & $5(-2$ to 11$)$ & 0.137 \\
\hline End-exercise & $101 \pm 15$ & $110 \pm 14$ & $9(2$ to 16$)$ & 0.012 \\
\hline End-exercise-baseline & $24 \pm 15$ & $28 \pm 13$ & $-4(-2$ to 11$)$ & 0.185 \\
\hline \multicolumn{5}{|l|}{ TRPG $\mathrm{mmHg}$} \\
\hline Baseline & $13.9 \pm 4.2$ & $22.8 \pm 5.5$ & $8.9(6.3$ to 11.5$)$ & $<0.001$ \\
\hline End-exercise & $20.0 \pm 7.4$ & $36.4 \pm 12.2$ & $16.4(10.8$ to 21.9$)$ & $<0.001$ \\
\hline End-exercise-baseline & $6.1 \pm 4.8$ & $13.6 \pm 10.5$ & 7.5 (2.8 to 12.2 ) & 0.002 \\
\hline \multicolumn{5}{|l|}{ Cardiac index L-min $\cdot \mathrm{m}^{-2}$} \\
\hline Baseline & $1.98 \pm 0.47$ & $2.36 \pm 0.58$ & $-0.38(-0.66$ to -0.09$)$ & 0.011 \\
\hline End-exercise & $4.00 \pm 1.17$ & $4.14 \pm 0.78$ & $-0.14(-0.62$ to 0.34$)$ & 0.566 \\
\hline End-exercise-baseline & $2.02 \pm 0.89$ & $1.78 \pm 0.61$ & $0.24(-0.13$ to 0.61$)$ & 0.206 \\
\hline \multicolumn{5}{|l|}{$\mathrm{SVI} \mathrm{L} \cdot \mathrm{min} \cdot \mathrm{m}^{-2}$} \\
\hline Baseline & $26.0 \pm 5.4$ & $29.2 \pm 6.8$ & $-3.3(-6.6$ to 0.1$)$ & 0.055 \\
\hline End-exercise & $38.6 \pm 6.6$ & $37.8 \pm 6.3$ & $0.8(-2.5$ to 4.1$)$ & 0.634 \\
\hline End-exercise-baseline & $12.6 \pm 3.7$ & $9.3 \pm 7.5$ & $3.4(0.0$ to 6.8$)$ & 0.052 \\
\hline \multicolumn{5}{|l|}{ TAPSE cm } \\
\hline Baseline & $2.1 \pm 0.3$ & $1.9 \pm 0.4$ & $-0.1(-0.3$ to 0.1$)$ & 0.153 \\
\hline End-exercise & $2.7 \pm 0.4$ & $2.5 \pm 0.5$ & $-0.2(-0.4$ to 0.1$)$ & 0.163 \\
\hline End-exercise-baseline & $0.6 \pm 0.4$ & $0.6 \pm 0.4$ & $0.0(-0.2$ to 0.2$)$ & 0.739 \\
\hline \multicolumn{5}{|l|}{ FAC $\%$} \\
\hline Baseline & $42.7 \pm 5.5$ & $41.7 \pm 8.1$ & $1.0(-6.3$ to 4.2$)$ & 0.691 \\
\hline End-exercise & $50.0 \pm 7.0$ & $44.0 \pm 7.7$ & $-6.0(-11.3$ to -0.8$)$ & 0.024 \\
\hline End-exercise-baseline & $7.8 \pm 7.5$ & $3.9 \pm 12.0$ & $-3.9(-12.7$ to 5.0$)$ & 0.380 \\
\hline \multicolumn{5}{|l|}{ RVEDA $\mathrm{cm}^{2}$} \\
\hline Baseline & $13.4 \pm 2.2$ & $18.1 \pm 3.7$ & $4.7(2.4$ to 7.1$)$ & $<0.001$ \\
\hline End-exercise & $17.6 \pm 2.7$ & $19.5 \pm 3.4$ & $1.8(-0.4$ to 4.1$)$ & 0.112 \\
\hline End-exercise-baseline & $3.5 \pm 1.8$ & $1.8 \pm 4.3$ & $-1.7(-4.7$ to 1.4$)$ & 0.275 \\
\hline \multicolumn{5}{|l|}{ RVESA $\mathrm{cm}^{2}$} \\
\hline Baseline & $7.7 \pm 18$ & $10.6 \pm 2.9$ & $2.9(1.0$ to 4.8$)$ & 0.003 \\
\hline End-exercise & $8.9 \pm 2.5$ & $10.9 \pm 2.2$ & $2.0(0.4$ to 3.6$)$ & 0.014 \\
\hline End-exercise-baseline & $0.6 \pm 1.3$ & $0.2 \pm 3.1$ & $-0.4(-2.6$ to 1.8$)$ & 0.707 \\
\hline \multicolumn{5}{|l|}{$\begin{array}{l}\text { TAPSE/TRPG } \\
\mathrm{mm} \cdot \mathrm{mmHg}^{-1}\end{array}$} \\
\hline Baseline & $1.6 \pm 0.5$ & $0.9 \pm 0.1$ & $-0.7(-0.9$ to -0.4$)$ & $<0.001$ \\
\hline End-exercise & $1.6 \pm 0.8$ & $0.8 \pm 0.3$ & $-0.8(-1.0$ to -0.5$)$ & $<0.001$ \\
\hline End-exercise-baseline & $-0.1 \pm 0.4$ & $-0.1 \pm 0.3$ & $-0.01(-0.20$ to 0.18$)$ & 0.901 \\
\hline \multicolumn{5}{|l|}{ TAPSE/sPAP $\mathrm{mm} \cdot \mathrm{mmHg}^{-1}$} \\
\hline Baseline & $1.1 \pm 0.3$ & $0.7 \pm 0.2$ & $-0.39(-0.52$ to -0.26$)$ & $<0.001$ \\
\hline End-exercise & $1.2 \pm 0.5$ & $0.7 \pm 0.3$ & $-0.50(-0.67$ to -0.34$)$ & $<0.001$ \\
\hline End-exercise-baseline & $-0.01 \pm 0.26$ & $-0.06 \pm 0.23$ & $-0.04(-0.17$ to 0.09$)$ & 0.515 \\
\hline \multicolumn{5}{|l|}{ BPs mmHg } \\
\hline Baseline & $104 \pm 19$ & $112 \pm 15$ & $7(-1$ to 15$)$ & 0.094 \\
\hline End-exercise & $123 \pm 20$ & $133 \pm 23$ & $9(-2$ to 20$)$ & 0.095 \\
\hline End-exercise-baseline & $19 \pm 12$ & $21 \pm 17$ & $2(-6$ to 10$)$ & 0.579 \\
\hline \multicolumn{5}{|l|}{$\mathrm{BPd} \mathrm{mmHg}$} \\
\hline Baseline & $70 \pm 11$ & $77 \pm 10$ & $7(1$ to 12$)$ & 0.015 \\
\hline End-exercise & $68 \pm 14$ & $78 \pm 13$ & $10(3$ to 17$)$ & 0.004 \\
\hline End-exercise-baseline & $-2 \pm 8$ & $2 \pm 12$ & $4(-2$ to 9$)$ & 0.191 \\
\hline
\end{tabular}

Data are presented as $n$, mean \pm SD or mean difference $(95 \% \mathrm{CI}$ ), unless otherwise stated. Baseline: baseline upright on cycle ergometer; end-exercise: values at end exercise; $S_{\mathrm{pO}_{2}}$ : oxygen saturation by pulse oximetry; TRPG: tricuspid regurgitation pressure gradient; SVI: stroke volume index; TAPSE: tricuspid annular plane systolic excursion; FAC: fractional area change; RVEDA: right ventricle end-diastolic area; RVESA: right ventricle end-systolic area; SPAP: systolic pulmonary artery pressure; BPs: blood pressure systolic; BPd: blood pressure diastolic. 

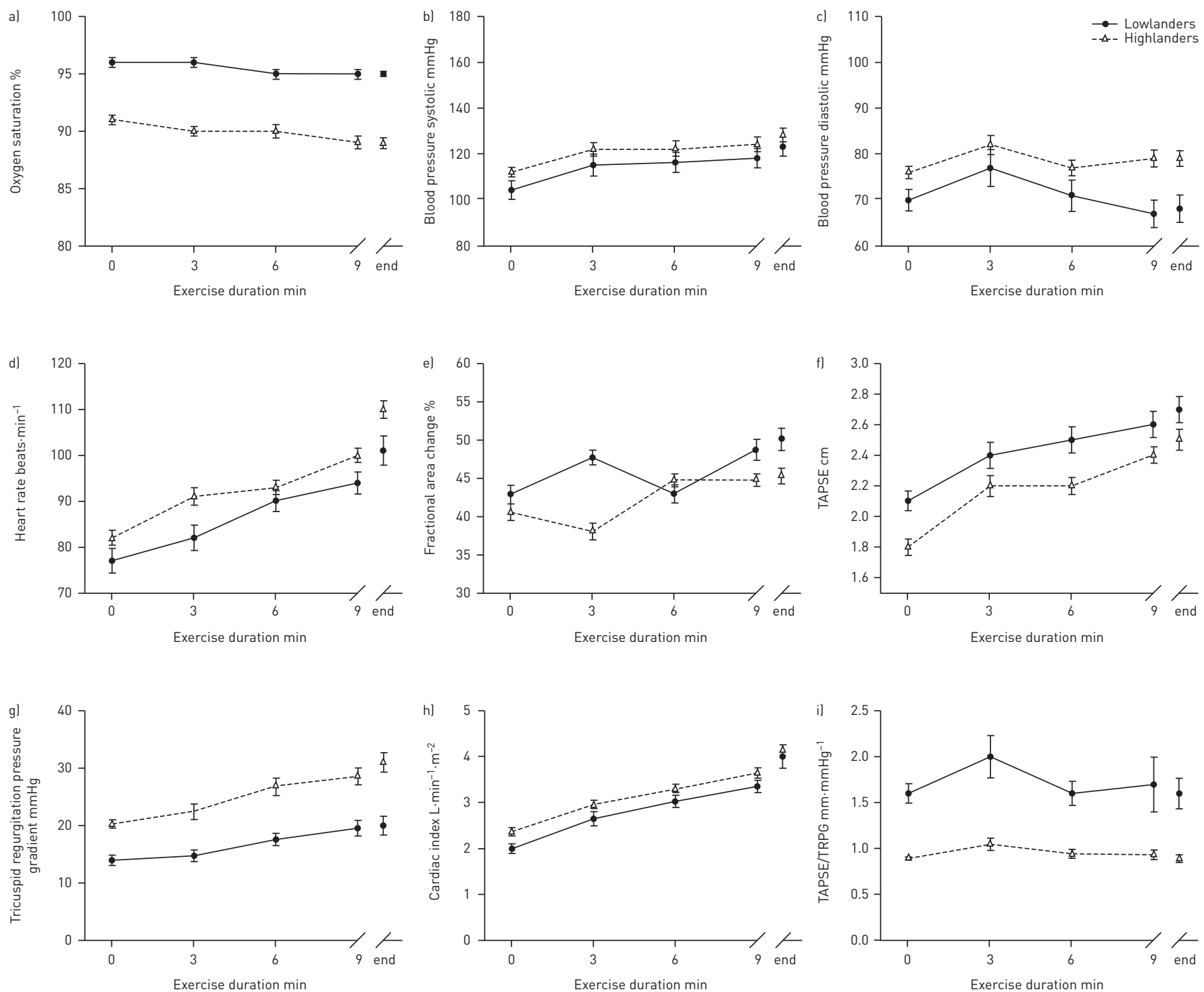

FIGURE 3 Vital signs of the lowlanders and highlanders during exercise (baseline, $3 \mathrm{~min}, 6 \mathrm{~min}, 9 \mathrm{~min}$ and individual end exercise). TAPSE: tricuspid annular plane systolic excursion; TRPG: tricuspid regurgitation pressure gradient.

and women. A different ethnicity with different genetic adaptation to altitude in the presently investigated Central Asian population compared with the Andean highlanders might lead to differently steep pressure-flow slopes However, we can only speculate, as to our knowledge there are no genetic factors known to date which may alter pulmonary haemodynamic response to exercise and this may be subject of future studies. Studies on the genetic adaptation up to now focussed on the difference in Andean, Tibetan and Ethiopian high-altitude dwellers but not on the response to exercise at altitude [17-19]. Patients assessed in the Andean region and summarised by SoRIA et al. [1] were assessed semi-supine, whereas our protocol included upright cycling, which is usually associated with a lower mPAP and cardiac index however resulting in an unchanged pressure-flow but higher pulmonary vascular resistance [20]. The cycling protocols used in the Andean studies were two steps at $25 \mathrm{~W}$ ( $3 \mathrm{~min}$ ) and $50 \mathrm{~W}$, whereas we used a stepwise increase of $10 \mathrm{~W}$ every $3 \mathrm{~min}$, which might have resulted in different cycling duration resulting in difficulties to compare the studies.

Reasons for the steeper increase of the PAP in highlanders compared with lowlanders are the chronic hypoxic pulmonary vasoconstriction and consecutive a reduced pulmonary vascular distensibility during exercise and hypervolaemia, polycythaemia and high blood viscosity [7]. The latter are more pronounced in patients with CMS [21]. However, resting arterial oxygen content was not different in the presently investigated highlanders compared with lowlanders, pointing towards an unchanged oxygen delivery to the tissue in regard of the slightly increased resting cardiac index and similar changes of $S_{\mathrm{pO}_{2}}$ and cardiac 
index during exercise [7]. A loss of vascular distensibility during exercise has been described as an early haemodynamic marker in patients with pulmonary vascular disease [22] and a steeper increase in pressure-flow relationship during exercise is known to be a predictor of survival in patients with pulmonary hypertension [23]. The relationship of the TRPG/cardiac index ratio decreases in lowlanders during exercise, whereas in highlanders with HAPH it increases in accordance with a much steeper pressure-flow slope $(\Delta \mathrm{TRPG} / \Delta \mathrm{CI})$, possibly indicating a worse distensibility or pulmonary arterial coupling. One other point might be that highlanders have a reduced pump function since heart rate increase is not significantly different but SVI increase was higher in lowlanders compared to highlanders during exercise albeit narrowly not significant $(p=0.052)$. However, the pressure-flow slope in the presently investigated highlanders living between 2500 and $3500 \mathrm{~m}$ was only slightly above the normal range and thus, the clinical relevance of this finding has to be further explored.

Highlanders have not only higher heart rate and systemic blood pressures but also a higher TRPG, cardiac index and an enlarged right ventricle compared with lowlanders at rest, albeit the reported values of right ventricular area are within the limits of normal according to the guidelines [24]. However, whether these normative values are applicable for Kyrgyz ethnicity remains unclear. Whether the enlarged right ventricle in highlanders versus lowlanders may reflect chronic strain, especially during exercise, relates to the slightly steeper pressure-flow relationship and would be associated with an exercise-induced increase in right atrial pressure remains to be determined.

Right ventricle-arterial coupling expressed as TAPSE/sPAP has been studied in patients with pulmonary hypertension and heart failure and TAPSE/sPAP at rest was an independent predictor of invasively assessed coupling [14, 25-27]. In these studies poor prognosis was defined by a cut-off value below $0.36 \mathrm{~mm} \cdot \mathrm{mmHg}^{-1}$ [28] and $0.31 \mathrm{~mm} \cdot \mathrm{mmHg}^{-1}$ [14]. In our study, TAPSE/TRPG and also TAPSE/sPAP at rest were $0.9 \pm 0.1$ respectively $0.8 \pm 0.3 \mathrm{~mm} \cdot \mathrm{mmHg}^{-1}$ and thus significantly worse compared to lowlanders and lower compared with previously published healthy European cohorts revealing a TAPSE/sPAP of $1.26 \pm 0.5$ [29]. TAPSE/TRPG resp. TAPSE/sPAP at end-exercise remained lower in highlanders compared with lowlanders, but interestingly there we found no worsening of the right ventricle coupling during exercise as it has been shown by D'Atтo et al. [30], which may indicate a preserved contractile reserve of the right heart in highlanders potentially reflecting adaption to high altitude. In contrast to the presently investigated highlander collective without CMS, Andean highlanders with CMS, where the capacity for altitude adaption is lost, present with right ventricular hypertrophy and dilatation and pulmonary vascular plexiform lesions [31]. The subgroup of highlanders with a resting $\mathrm{mPAP}>30 \mathrm{mmHg}$ which can be diagnosed as HAPH presented with a reduced right ventricle-arterial coupling reflected by a significantly lower TAPSE/TRPG at end-exercise albeit still within the normal range.

The proportion of highlanders with HAPH depends on the definition used and many of which fulfilling certain definitions are clinically oligosymptomatic and the natural course of PAP increase at altitude is insufficiently known. Thus, it is not known which cut-off of PAP or PVR at rest is associated with right heart failure and premature death and whether a steeper pressure-flow slope during exercise would be predictive for worse outcome in this population, such it has been shown in lowlanders with pulmonary arterial or chronic thromboembolic pulmonary hypertension [23] and in patients with systemic sclerosis with exercise induced pulmonary hypertension [32]. Whether the increase in pressure-flow relationship or worsening of right ventricular pulmonary arterial coupling are of prognostic relevance in highlanders has not been studied so far and remains to be elucidated. Furthermore, genetic factors might play a role as has been previously postulated [33].

\section{Limitations}

Pulmonary haemodynamics were assessed by echocardiography at rest and during exercise, as the golden standard, right heart catheterisation, was not possible for logistical and ethical reasons. However, stress echocardiography has been shown to be sufficiently accurate, but potentially less precise [8]. Subjects with elevated haemoglobin $>19 \mathrm{~g} \cdot \mathrm{dL}^{-1}$ in females and $>21 \mathrm{~g} \cdot \mathrm{dL}^{-1}$ in males, were not included in the current trial aiming to exclude patients possibly suffering from CMS. Therefore, we cannot present haemodynamic changes with exercise for these patients, as most published studies on stress echocardiography at altitude focussed on the difference between highlanders with and without CMS [1]. This trial focussed on the comparison of highlanders without CMS compared with lowlanders. The results of the current trial may include a selection bias as patients without two valid TRPG measures during exercise were not included in the analysis, presumably excluding patients with very low PAP in highlanders, but also lowlanders.

In conclusion, the present study is the first to investigate a large collective of Central Asian highlanders living at moderate-to-high altitude between 2500 and $3500 \mathrm{~m}$ by stress echocardiography compared with lowlanders. The main results are that highlanders reveal a significantly higher PAP over all exercise steps together with a similar cardiac index resulting in a steeper pressure-flow slope, as indicator of an increased 
pulmonary resistance and potential sign of early pulmonary hypertension, which was most pronounced in highlanders with an elevated PAP already at rest thus qualifying as $\mathrm{HAPH}$, intermediate in patients with borderline resting PAP increase and lowest in patients with normal resting haemodynamics. Whether the steeper pressure-flow increase with exercise predicts worse outcome in these highlanders remains to be studied.

Conflict of interest: S. Ulrich reports grants from Zurich Lung League and the Swiss National Science Foundation during the conduct of the study; grants and personal fees from Actelion SA, personal fees from Bayer SA and MSD, and grants and personal fees from Orpha Swiss, outside the submitted work. S. Saxer has nothing to disclose. M. Furian has nothing to disclose. P.R. Bader has nothing to disclose. P. Appenzeller has nothing to disclose. P.M. Scheiwiller has nothing to disclose. M. Mademilov has nothing to disclose. U. Sheraliev has nothing to disclose. F. Tanner has nothing to disclose. T.M. Sooronbaev has nothing to disclose. K.E. Bloch reports grants from the Zurich Lung League and the Swiss National Science Foundation during the conduct of the study. M. Lichtblau has nothing to disclose.

Support statement: The study was funded by OPO foundation (Zurich, Switzerland). Funding information for this article has been deposited with the Crossref Funder Registry.

\section{References}

1 Soria R, Egger M, Scherrer U, et al. Pulmonary arterial pressure at rest and during exercise in chronic mountain sickness: a meta-analysis. Eur Respir J 2019; 53: 1802040.

2 Soria R, Egger M, Scherrer U, et al. Pulmonary artery pressure and arterial oxygen saturation in people living at high or low altitude: systematic review and meta-analysis. J Appl Physiol (1985) 2016; 121: 1151-1159.

3 Stuber T, Sartori C, Schwab M, et al. Exaggerated pulmonary hypertension during mild exercise in chronic mountain sickness. Chest 2010; 137: 388-392.

4 Lichtblau M, Saxer S, Furian M, et al. Cardiac function and pulmonary hypertension in Central Asian highlanders at $3250 \mathrm{~m}$. Eur Respir J 2020; 56: 1902474.

5 Kovacs G, Herve P, Barbera JA, et al. An official European Respiratory Society statement: pulmonary haemodynamics during exercise. Eur Respir J 2017; 50: 1700578.

6 Herve P, Lau EM, Sitbon O, et al. Criteria for diagnosis of exercise pulmonary hypertension. Eur Respir J 2015; 46: 728-737.

7 Banchero N, Sime F, Penaloza D, et al. Pulmonary pressure, cardiac output, and arterial oxygen saturation during exercise at high altitude and at sea level. Circulation 1966; 33: 249-262.

8 Claessen G, La Gerche A, Voigt JU, et al. Accuracy of echocardiography to evaluate pulmonary vascular and RV function during exercise. JACC Cardiovasc Imaging 2016; 9: 532-543.

9 Kojonazarov BK, Imanov BZ, Amatov TA, et al. Noninvasive and invasive evaluation of pulmonary arterial pressure in highlanders. Eur Respir J 2007; 29: 352-356.

10 Evangelista A, Flachskampf F, Lancellotti P, et al. European Association of Echocardiography recommendations for standardization of performance, digital storage and reporting of echocardiographic studies. Eur J Echocardiogr 2008; 9: 438-448.

11 Lichtblau M, Bader PR, Saxer S, et al. Right atrial pressure during exercise predicts survival in patients with pulmonary hypertension. J Am Heart Assoc 2020; 9: e018123.

12 Chemla D, Castelain V, Humbert $\mathrm{M}$, et al. New formula for predicting mean pulmonary artery pressure using systolic pulmonary artery pressure. Chest 2004; 126: 1313-1317.

13 Huntsman LL, Stewart DK, Barnes SR, et al. Noninvasive Doppler determination of cardiac output in man. Clinical validation. Circulation 1983; 67: 593-602.

14 Tello K, Wan J, Dalmer A, et al. Validation of the tricuspid annular plane systolic excursion/systolic pulmonary artery pressure ratio for the assessment of right ventricular-arterial coupling in severe pulmonary hypertension. Circ Cardiovasc Imaging 2019; 12: e009047.

15 Naeije R, Vanderpool R. Pulmonary hypertension and chronic mountain sickness. High Alt Med Biol 2013; 14: $117-125$.

16 Argiento P, Vanderpool RR, Mule M, et al. Exercise stress echocardiography of the pulmonary circulation: limits of normal and sex differences. Chest 2012; 142: 1158-1165.

17 Bigham AW, Wilson MJ, Julian CG, et al. Andean and Tibetan patterns of adaptation to high altitude. Am J Hum Biol 2013; 25: 190-197.

18 Eichstaedt CA, Antao T, Pagani L, et al. The Andean adaptive toolkit to counteract high altitude maladaptation: genome-wide and phenotypic analysis of the Collas. PLoS One 2014; 9: e93314.

19 Lorenzo FR, Huff C, Myllymaki M, et al. A genetic mechanism for Tibetan high-altitude adaptation. Nat Genet 2014; 46: 951-956.

20 Bevegard S, Holmgren A, Jonsson B. The effect of body position on the circulation at rest and during exercise, with special reference to the influence on the stroke volume. Acta Physiol Scand 1960; 49: 279-298.

21 Groepenhoff H, Overbeek MJ, Mule M, et al. Exercise pathophysiology in patients with chronic mountain sickness exercise in chronic mountain sickness. Chest 2012; 142: 877-884.

22 Lau EMT, Chemla D, Godinas L, et al. Loss of vascular distensibility during exercise is an early hemodynamic marker of pulmonary vascular disease. Chest 2016; 149: 353-361.

23 Hasler ED, Muller-Mottet S, Furian M, et al. Pressure-flow during exercise catheterization predicts survival in pulmonary hypertension. Chest 2016; 150: 57-67.

24 Rudski LG, Lai WW, Afilalo J, et al. Guidelines for the echocardiographic assessment of the right heart in adults: a report from the American Society of Echocardiography endorsed by the European Association of Echocardiography, a registered branch of the European Society of Cardiology, and the Canadian Society of Echocardiography. J Am Soc Echocardiogr 2010; 23: 685-713. quiz 786-688.

25 Spruijt $\mathrm{OA}$, de Man FS, Groepenhoff $\mathrm{H}$, et al. The effects of exercise on right ventricular contractility and right ventricular-arterial coupling in pulmonary hypertension. Am J Respir Crit Care Med 2015; 191: 1050-1057. 
Trip P, Rain S, Handoko ML, et al. Clinical relevance of right ventricular diastolic stiffness in pulmonary hypertension. Eur Respir J 2015; 45: 1603-1612.

27 Vanderpool RR, Pinsky MR, Naeije R, et al. RV-pulmonary arterial coupling predicts outcome in patients referred for pulmonary hypertension. Heart 2015; 101: 37-43.

28 Guazzi M. Use of TAPSE/PASP ratio in pulmonary arterial hypertension: An easy shortcut in a congested road Int J Cardiol 2018; 266: 242-244.

29 Ferrara F, Rudski LG, Vriz O, et al. Physiologic correlates of tricuspid annular plane systolic excursion in 1168 healthy subjects. Int J Cardiol 2016; 223: 736-743.

30 D'Alto M, Pavelescu A, Argiento P, et al. Echocardiographic assessment of right ventricular contractile reserve in healthy subjects. Echocardiography 2017; 34: 61-68.

31 Penaloza D, Arias-Stella J. The heart and pulmonary circulation at high altitudes: healthy highlanders and chronic mountain sickness. Circulation 2007; 115: 1132-1146.

32 Stamm A, Saxer S, Lichtblau M, et al. Exercise pulmonary haemodynamics predict outcome in patients with systemic sclerosis. Eur Respir J 2016: 48: 1658-1667.

33 Wilkins MR, Aldashev AA, Wharton J, et al. alpha1-A680T variant in GUCY1A3 as a candidate conferring protection from pulmonary hypertension among Kyrgyz highlanders. Circ Cardiovasc Genet 2014; 7: 920-929. 